\title{
Dietary intake of antioxidant (pro)-vitamins, respiratory symptoms and pulmonary function: the MORGEN study
}

\author{
Linda Grievink, Henriëtte A Smit, Marga C Ocké, Pieter van 't Veer, Daan Kromhout
}

\begin{abstract}
Background-A study was undertaken to investigate the relationships between the intake of the antioxidant (pro)-vitamins $C, E$ and $\beta$-carotene and the presence of respiratory symptoms and lung function. Methods-Complete data were collected in a cross sectional study in a random sample of the Dutch population on 6555 adults during 1994 and 1995. Antioxidant intake was assessed by a semi-quantitative food frequency questionnaire and respiratory symptoms (cough, phlegm, productive cough, wheeze, shortness of breath) were assessed by a self-administered questionnaire. Prevalence odds ratios for symptoms were calculated using logistic regression analysis. Linear regression analysis was used for forced expiratory volume in one second $\left(F E V_{1}\right)$ and forced vital capacity (FVC). The results are presented as a comparison between the 90th and 10th percentiles of antioxidant intake.
\end{abstract}

Results-Vitamin C intake was not associated with most symptoms but was inversely related with cough. Subjects with a high intake of vitamin $\mathrm{C}$ had a $53 \mathrm{ml}(95 \%$ CI 23 to 83) higher $\mathrm{FEV}_{1}$ and $79 \mathrm{ml}(95 \% \mathrm{CI}$ 42 to 116) higher FVC than those with a low vitamin $C$ intake. Vitamin $E$ intake showed no association with most symptoms and lung function, but had a positive association with productive cough. The intake of $\beta$-carotene was not associated with most symptoms but had a positive association with wheeze. However, subjects with a high intake of $\beta$-carotene had a $60 \mathrm{ml}(95 \% \mathrm{CI} 31$ to 89$)$ higher $\mathrm{FEV}_{1}$ and 75 $\mathrm{ml}(95 \%$ CI 40 to 110) higher FVC than those with a low intake of $\beta$-carotene. Conclusions-The results of this study suggest that a high intake of vitamin $C$ or $\beta$-carotene is protective for $\mathrm{FEV}_{1}$ and FVC compared with a low intake, but not for respiratory symptoms.

(Thorax 1998;53:166-171)

Keywords: antioxidants; lung function; respiratory symptoms
Diet is a relatively new area of interest in the field of asthma and chronic obstructive pulmonary disease (COPD). Antioxidant vitamins are considered to be potentially protective factors in the respiratory system because antioxidants in the lung can scavenge endogenous and/or environmental oxidant sources. ${ }^{1-3}$

A protective effect of fruit consumption has been reported for lung function ${ }^{45}$ and for chronic non-specific lung disease (CNSLD). ${ }^{6}$ In cross sectional studies a higher intake of vitamin $\mathrm{C}^{78}$ was associated with larger lung volumes; a higher plasma concentration of vitamin $\mathrm{C}$ was associated with larger lung volumes in adults ${ }^{9}$ but not in children, ${ }^{5}$ and a lower prevalence of wheeze and chronic bronchitis, ${ }^{10}$ suggesting a protective effect of vitamin $\mathrm{C}$ on respiratory disease in adults. The prospective Zutphen study did not show an association between the intake of vitamin $\mathrm{C}$ or $\beta$-carotene and the incidence of CNSLD. ${ }^{6}$ The Nurses Health Study showed no association between dietary vitamin $C$ and the incidence of asthma but dietary $\beta$-carotene and vitamin $\mathrm{E}$ were inversely related to adult onset asthma. ${ }^{11}$ In summary, no consistent pattern arises from these studies on the relationship between antioxidant (pro)-vitamin intake and respiratory disease. To our knowledge no results on the relationship between dietary $\beta$-carotene and lung function have been published.

The MORGEN study (the monitoring project on risk factors and health in the Netherlands) provided the opportunity to investigate the relationships between the intake of the antioxidants (vitamins C, E or $\beta$-carotene) and the prevalence of a number of respiratory symptoms and lung function simultaneously.

\section{Methods}

STUDY POPULATION

The MORGEN study is a cross sectional investigation of the prevalence of risk factors for chronic diseases using self-administered questionnaires and a physical examination in a randomly selected sample of the Dutch population aged 20-59 years in three towns in the Netherlands (Amsterdam, Doetinchem, and Maastricht). The average response rate of the three towns was $50 \%$. A total of 8695 subjects were enrolled in 1994 and 1995 for question- 
naires and physical examination. Of these, 683 subjects did not perform a lung function measurement for practical reasons such as non-availability of lung function devices, time constraints, etc. Of the remaining 8012 subjects with lung function measurements we excluded pregnant women ( $\mathrm{n}=47)$, supplement users $(n=688)$, and those with missing values on one or more of the confounders ( $\mathrm{n}=$ 722 ). Thus, the population for data analysis consisted of 6555 individuals.

\section{DATA COLLECTION}

Invitations to participate in the study were sent to a random sample of the population by municipal health services. Those subjects who agreed to participate received two selfadministered questionnaires (general and semi-quantitative food frequency) and underwent a physical examination. The general questionnaire provided information about demographic variables, life style factors (smoking, physical activity, alcohol consumption), environmental factors (presence of pets, dampness of the house, indoor $\mathrm{NO}_{2}$ sources), chronic respiratory symptoms, and the presence of other chronic diseases (diabetes, migraine, low back pain, neck and shoulder pain). The physical examination included measurements of height, weight, waist-hip circumference, blood pressure, and lung function. Blood (non-fasting) samples were taken for determination of glucose, total and HDL cholesterol.

For the present analyses we defined chronic respiratory symptoms as positive answers to the following questions: "Do you cough when getting up during winter time on most days for at least three months a year?" (cough), "Do you bring up phlegm when getting up during winter time on most days for at least three months a year?" (phlegm), "Have you had productive cough for a period of three weeks in the last three years?" (productive cough), "Have you been troubled by wheezing, not due to a cold or the flu, in the last 12 months?" (wheeze), "Are you short of breath when walking with other people of your own age on level ground?" (shortness of breath), and "Are you being woken by attacks of shortness of breath?" (nocturnal attacks of shortness of breath). These questions on respiratory symptoms were selected from the Dutch part of the European Community Respiratory Health Survey. ${ }^{12} 13$

Lung function was measured with a heated pneumotachometer (Jaeger, Germany). Calibration took place twice a day. Measurements were performed by trained paramedics. Subjects were seated in an upright posture with a fixed mouthpiece which was adjusted for the height of each individual and, in addition, a nose clip was used. A maximum of eight manoeuvres was performed. Subjects who did not achieve at least three technically acceptable (of which two were reproducible) manoeuvres of BTPS corrected forced expiratory volume in one second $\left(\mathrm{FEV}_{1}\right)$ or forced vital capacity (FVC) according to ERS 1993 criteria $^{14}$ were excluded from either the $\mathrm{FEV}_{1}$ or FVC analyses, or both. Analyses were based on the maximum value of the reproducible manoeuvres of $\mathrm{FEV}_{1}$ and FVC. Pregnant women were not considered in data analysis because the actual lung function could have been attenuated. ${ }^{15}$

The food frequency questionnaire was developed for the MORGEN study which is part of the Dutch cohort of the EPIC study (European Prospective Investigation into Cancer and Nutrition). ${ }^{16}$ The purpose of the questionnaire was, in particular, to quantify energy and antioxidant intake. ${ }^{17} 18$ The habitual consumption of 178 food items during the last year was calculated from the questionnaire. Nutrient and energy intake were quantified for each individual using an extended version of the 1993 computerised Dutch food composition table. ${ }^{19}$ In 1991 and 1992 the reproducibility and relative validity of the food groups and nutrients were assessed in a validation study. ${ }^{17}{ }^{18}$ The structure of the food frequency questionnaire did not allow a calculation of the nutrient contribution of vitamin supplements. About $9 \%$ of the total study population had used daily vitamin supplements in the last 12 months (vitamin A, C, E and multivitamins; $\beta$-carotene is not a common constituent in any of the supplements in the Netherlands). Since this number of subjects was too small to be considered in separate analyses they were excluded from the data analysis to reduce possible misclassification of nutrient intake.

DEFINITION OF VARIABLES

The subjects were grouped into three categories according to their educational level: low (intermediate secondary education or less), intermediate (intermediate vocational or higher secondary education), and high (higher vocational or university education). Current smokers were defined as those smoking one or more cigarette(s) a day. Pack-years of smoking were defined for current and former smokers, one pack-year being equal to smoking 20 cigarettes a day for one year.

\section{STATISTICAL ANALYSIS}

The shape of the relationship between each antioxidant and respiratory symptoms or lung function was investigated by classifying the antioxidants into quintiles of intake. The cut off points for each quintile were based on the distribution of the intake of subjects without any chronic respiratory symptoms. Since no essential deviation from linearity was observed, the intake of the antioxidant vitamins C, E and $\beta$-carotene were entered as continuous independent variables in logistic and linear regression models.

The presence of each respiratory symptom (cough, phlegm, productive cough, wheeze or shortness of breath, and nocturnal attacks of shortness of breath) was used as the dependent variable in logistic regression analyses. ${ }^{20}$ The independent variable of interest was the intake of antioxidants as a continuous variable. Prevalence odds ratios (ORs) with $95 \%$ confidence intervals (95\% CI) were estimated using logistic regression analysis; ORs were presented as a 
Table 1 Mean (SD) characteristics for total population $(n=6555)$ and for subjects with and without technically acceptable and reproducible measurements of $F E V_{1}$

\begin{tabular}{|c|c|c|c|}
\hline Characteristics & $\begin{array}{l}\text { Total population } \\
(n=6555)\end{array}$ & $\begin{array}{l}\text { Reproducible FEV } \\
(n=5740)\end{array}$ & $\begin{array}{l}\text { Non-reproducible FEV } V_{1}^{\dagger} \\
(n=815)\end{array}$ \\
\hline Age (years) & $42.1(11.0)$ & $41.7(10.9)$ & $44.7(10.9)$ \\
\hline Height (m) & $1.72(0.094)$ & $1.72(0.093)$ & $1.69(0.097)$ \\
\hline Sex (\% women $)$ & 52.3 & 51.9 & 55.6 \\
\hline \multicolumn{4}{|l|}{ Smoking status (\%) } \\
\hline Current smokers & 32.4 & 32.7 & 30.6 \\
\hline Former smokers & 31.2 & 31.6 & 28.5 \\
\hline Never smokers & 36.3 & 35.7 & 41.0 \\
\hline Pack-years ${ }^{\star}$ & $17.4(15.4)$ & $17.2(15.1)$ & $18.8(16.9)$ \\
\hline \multicolumn{4}{|l|}{$\begin{array}{l}\text { Educational level } \\
(\%)\end{array}$} \\
\hline Low & 48.2 & 46.2 & 62.7 \\
\hline Intermediate & 29.3 & 30.3 & 21.6 \\
\hline High & 22.5 & 23.5 & 15.7 \\
\hline $\mathrm{BMI}\left(\mathrm{kg} / \mathrm{m}^{2}\right)$ & $25.4(3.9)$ & $25.3(3.9)$ & $26.2(4.3)$ \\
\hline Physical activity (\%) & 64.5 & 65.8 & 55.4 \\
\hline Alcohol use (\% yes) & 60.9 & 62.2 & 51.4 \\
\hline $\begin{array}{l}\text { Respiratory } \\
\text { symptoms }\end{array}$ & 32.7 & 32.1 & 36.5 \\
\hline
\end{tabular}

*Excluding those subjects who never smoked.

${ }^{* *}$ One or more of the following respiratory symptoms: cough, phlegm, productive cough, wheeze, shortness of breath, nocturnal attacks of shortness of breath, ever asthma.

'Including those subjects who were not able to perform at least three lung function manoeuvres (n $=452$ ).

Table 2 Mean (SD) energy and nutrient intake per day of nutrients for the total population $(n=6555)$ and for subjects with and without technically acceptable and reproducible measurements of $F E V_{1}$

\begin{tabular}{llll}
\hline Nutrients & $\begin{array}{l}\text { Total } \\
(n=6555)\end{array}$ & $\begin{array}{l}\text { Reproducible FEV } \\
(n=5740)\end{array}$ & $\begin{array}{l}\text { Non-reproducible FEV }{ }_{1}^{\dagger} \\
(n=815)\end{array}$ \\
\hline Energy (MJ) & $9.8(2.9)$ & $9.8(2.9)$ & $9.7(3.1)$ \\
Protein (en\%) & $15.3(2.3)$ & $15.3(2.3)$ & $15.3(2.6)$ \\
Fat (en\%) & $35.7(5.2)$ & $35.7(5.2)$ & $35.6(5.4)$ \\
Carbohydrates (en\%) & $45.2(6.4)$ & $45.1(6.4)$ & $45.6(6.7)$ \\
Alcohol (en\%) & $3.6(4.6)$ & $3.6(4.6)$ & $3.2(4.9)$ \\
Vitamin C (mg) & $132.6(61.7)$ & $132.6(61.7)$ & $132.5(62.1)$ \\
Vitamin E (mg) & $16.3(6.0)$ & $16.3(5.9)$ & $16.1(6.2)$ \\
$\beta$-carotene (mg) & $2.33(1.11)$ & $2.34(1.10)$ & $2.28(1.15)$ \\
\hline
\end{tabular}

${ }^{*}$ Protein, fat, carbohydrates and alcohol are expressed as a percentage of energy intake. ${ }^{\dagger}$ Including those subjects who were not able to perform at lease three lung function manoeuvres $(\mathrm{n}=452)$.

comparison of antioxidant intake in the 90th and 10th percentiles.

Models for $\mathrm{FEV}_{1}$ and FVC were fitted with multiple linear regression. ${ }^{20}$ To select a basic model for $\mathrm{FEV}_{1}$ and FVC, taking account of sex, height and age, we considered several models using different powers of height and age. The choice of the "best" model was based on assessment of model simplicity, analysis of residuals, and the percentage of variance in $\mathrm{FEV}_{1}$ and FVC explained by the model. We chose the following basic adjusted model: $\mathrm{FEV}_{1}$ and FVC divided by height squared as dependent variable with age, age squared, and sex as independent variables. Regression coefficients (in $\mathrm{ml}$ ) were calculated for a standard height of $1.70 \mathrm{~m}$ and were expressed as the difference in $\mathrm{FEV}_{1}$ and FVC between subjects in the 90th and 10th percentiles of antioxidant intake.

The following confounding factors were considered as independent variables in the model: smoking status, pack years of smoking, educational level, town, energy intake (to standardise the intake of the antioxidants), body mass index (weight in $\mathrm{kg}$ divided by height in metres squared), alcohol consumption, physical activity (yes/no), the other two antioxidant (pro)-vitamins, medical treatment for hay fever (yes/no), and environmental factors such as the presence of pets (never/not anymore/currently present), dampness of the house by questions on the presence of damp or mould spots on the walls of homes during the last two years, gas cooking (yes/no), and the presence of an unvented (gas-fired) water heater (yes/no) (as predominant indoor source of $\mathrm{NO}_{2}$ in homes). In the final models the following variables were adjusted for: age, sex, energy intake, smoking status, and pack years of smoking. Adjustment for educational level was considered to be an over-adjustment in the relationship between antioxidants and lung function or respiratory symptoms so we did not adjust for educational level. We were not able to perform statistical evaluation of the presence of effect modification of smoking status on the relationship between antioxidants and lung function or respiratory symptoms because of the small numbers in each group. In addition, we could not study the independent effect of the intake of vitamin $C$ and $\beta$-carotene adjusting for each other because these two antioxidants are present in the same food groups, such as fruits and vegetables, resulting in a relatively high Spearman correlation coefficient $(r=$ $0.60)$.

\section{Results}

Of the 6555 subjects available for analyses, 6103 had at least three technically acceptable lung function manoeuvres of whom 5740 subjects had reproducible measurements for $\mathrm{FEV}_{1}$ and 5633 subjects for FVC.

Table 1 shows the characteristics of the total study population for subjects with and without reproducible $\mathrm{FEV}_{1}$ measurements. We note that the subjects without reproducible $\mathrm{FEV}_{1}$ measurements consisted of those who could not perform three technically acceptable measurements $(\mathrm{n}=452)$ plus subjects who met acceptability criteria but not the reproducibility criteria $(n=363)$. The characteristics for subjects with and without reproducible FVC measurements were similar to those subjects with and without reproducible $\mathrm{FEV}_{1}$ measurements, therefore we only present the latter. For the total population the mean age was 42 years; approximately one third of the study population were current smokers and about half had a low educational level. Subjects without reproducible $\mathrm{FEV}_{1}$ measurements were older, had a lower educational level and were less physically active but included more never smokers and less alcohol consumers. Table 2 shows that the mean energy and nutrient intake was not different in subjects with or without reproducible $\mathrm{FEV}_{1}$ measurements; the same was observed for non-reproducible versus reproducible FVC measurements (data not shown).

Possible confounding factors such as sex, smoking status, and educational level were evaluated. The intake of antioxidants was found to be related to these factors. Women had a higher intake of vitamin $C$ and $\beta$-carotene but a lower intake of vitamin $E$ than men, and current smokers had a lower intake of vitamin $\mathrm{C}$ and $\beta$-carotene but a higher intake of vitamin $\mathrm{E}$ than never smokers. The mean intake of the antioxidants was highest in the 
Table 3 Prevalence of respiratory symptoms (\%) and mean FVC (l) and FEV (l) by quintiles of antioxidants

\begin{tabular}{|c|c|c|c|c|c|c|c|c|c|c|c|c|c|c|c|}
\hline & \multicolumn{5}{|c|}{ Quintiles $^{t}$ of vitamin C intake } & \multicolumn{5}{|c|}{ Quintiles $^{t}$ of vitamin E intake } & \multicolumn{5}{|c|}{ Quintiles $^{\dagger}$ of $\beta$-carotene intake } \\
\hline & 1 & 2 & 3 & 4 & 5 & 1 & 2 & 3 & 4 & 5 & 1 & 2 & 3 & 4 & 5 \\
\hline Number of subjects & 1392 & 1314 & 1249 & 1263 & 1335 & 1247 & 1333 & 1249 & 1330 & 1396 & 1319 & 1283 & 1295 & 1262 & 1396 \\
\hline Cough (\%) & 10.2 & 7.0 & 6.4 & 4.7 & 5.3 & 6.3 & 7.1 & 6.4 & 6.0 & 8.0 & 7.8 & 6.9 & 7.1 & 5.6 & 6.3 \\
\hline Phlegm (\%) & 7.9 & 6.1 & 6.8 & 5.0 & 4.8 & 5.0 & 6.5 & 5.7 & 6.3 & 7.0 & 6.8 & 6.9 & 5.4 & 4.8 & 6.8 \\
\hline Prod. cough (\%) & 17.3 & 17.6 & 16.0 & 16.9 & 19.1 & 14.1 & 16.3 & 17.2 & 18.6 & 20.5 & 16.6 & 15.2 & 17.5 & 17.0 & 20.4 \\
\hline Wheeze $(\%)$ & 10.8 & 7.7 & 7.8 & 6.7 & 8.8 & 9.0 & 8.9 & 7.7 & 7.1 & 9.2 & 8.0 & 9.3 & 7.1 & 7.6 & 9.9 \\
\hline SOB $(\%)$ & 9.0 & 4.4 & 5.7 & 3.4 & 5.9 & 7.6 & 5.8 & 4.5 & 5.2 & 5.5 & 6.7 & 6.3 & 4.9 & 5.5 & 5.2 \\
\hline $\begin{array}{l}\text { Noct. attacks SOB } \\
(\%)\end{array}$ & 6.0 & 5.5 & 4.7 & 4.9 & 5.6 & 5.8 & 6.5 & 4.3 & 4.2 & 6.0 & 5.1 & 5.9 & 4.7 & 4.7 & 6.5 \\
\hline Number of subjects & 1199 & 1170 & 1103 & 1114 & 1154 & 1069 & 1164 & 1117 & 1168 & 1222 & 1131 & 1118 & 1141 & 1111 & 1239 \\
\hline $\mathrm{FEV}_{1}(\mathrm{l})$, unadjusted & 3.50 & 3.63 & 3.58 & 3.65 & 3.62 & 3.29 & 3.48 & 3.60 & 3.72 & 3.84 & 3.44 & 3.53 & 3.62 & 6.50 & 3.72 \\
\hline $\mathrm{FEV}_{1}(1)$, adjusted ${ }^{\star}$ & 3.38 & 3.50 & 3.47 & 3.52 & 3.52 & 3.43 & 3.48 & 3.48 & 3.50 & 3.48 & 3.41 & 3.44 & 3.49 & 3.51 & 3.53 \\
\hline Number of subjects & 1191 & 1150 & 1072 & 1080 & 1140 & 1051 & 1143 & 1100 & 1141 & 1198 & 1116 & 1105 & 1124 & 1080 & 1208 \\
\hline FVC (1), unadjusted & 4.48 & 4.60 & 4.56 & 4.64 & 4.56 & 4.20 & 4.40 & 4.55 & 4.76 & 4.89 & 4.41 & 4.50 & 4.62 & 4.64 & 4.68 \\
\hline FVC (1), adjusted ${ }^{\star}$ & 4.29 & 4.42 & 4.41 & 4.47 & 4.47 & 4.34 & 4.41 & 4.40 & 4.45 & 4.44 & 4.33 & 4.36 & 4.44 & 4.45 & 4.46 \\
\hline
\end{tabular}

SOB $=$ shortness of breath.

${ }^{*}$ Mean $\mathrm{FEV}_{1}$ and FVC adjusted for age, age squared and sex, presented for a height of $1.70 \mathrm{~m}$.

tThe cut off points for each quintile were based on the distribution of the intake of subjects without any chronic respiratory symptoms.

Table 4 Relationship between antioxidants (vitamin $C$, vitamin $E$, and $\beta$-carotene) and respiratory symptoms or lung function $(n=6555)$

\begin{tabular}{|c|c|c|c|c|c|c|c|c|c|}
\hline \multirow[b]{2}{*}{ Dependent variable } & \multicolumn{3}{|l|}{ Vitamin $C$} & \multicolumn{3}{|l|}{ Vitamin $E$} & \multicolumn{3}{|l|}{$\beta$-carotene } \\
\hline & $O R^{*}$ & $O R^{t}$ & $95 \% C I^{t}$ & $O R^{*}$ & $O R^{\dagger}$ & $95 \% C I^{t}$ & $O R^{*}$ & $O R^{\dagger}$ & $95 \% C I^{t}$ \\
\hline \multicolumn{10}{|l|}{ Symptoms } \\
\hline Cough $(n=6533)$ & 0.53 & 0.66 & 0.50 to 0.87 & 1.28 & 0.85 & 0.61 to 1.18 & 0.79 & 0.86 & 0.67 to 1.10 \\
\hline Phlegm $(n=6541)$ & 0.67 & 0.77 & 0.59 to 1.02 & 1.32 & 1.06 & 0.76 to 1.47 & 1.04 & 1.11 & 0.87 to 1.40 \\
\hline $\begin{array}{l}\text { Productive cough } \\
(\mathrm{n}=6536)\end{array}$ & 1.08 & 1.09 & 0.93 to 1.28 & 1.47 & 1.26 & 1.02 to 1.56 & 1.20 & 1.14 & 0.99 to 1.33 \\
\hline Wheeze $(n=6514)$ & 0.87 & 1.04 & 0.83 to 1.30 & 1.18 & 1.13 & 0.85 to 1.52 & 1.15 & 1.27 & 1.04 to 1.55 \\
\hline SOB $(n=6494)$ & 0.75 & 0.81 & 0.61 to 1.07 & 0.88 & 1.24 & 0.87 to 1.77 & 0.87 & 1.00 & 0.77 to 1.29 \\
\hline $\begin{array}{l}\text { Nocturnal attacks SOB } \\
(\mathrm{n}=6539)\end{array}$ & 0.90 & 0.95 & 0.72 to 1.25 & 1.10 & 1.20 & 0.84 to 1.71 & 1.16 & 1.22 & 0.96 to 1.56 \\
\hline Lung function & Difference $^{\ddagger}$ & Difference ${ }^{\mathfrak{S}}$ & $95 \% C I^{\S}$ & Difference $^{*}$ & Difference & $95 \% C I^{5}$ & Difference $^{*}$ & Difference & $95 \% C I^{\Im}$ \\
\hline $\mathrm{FEV}_{1}(\mathrm{n}=5740)$ & 91.1 & 52.9 & 23.0 to 82.3 & 33.0 & 27.9 & -12.9 to 68.7 & 83.2 & 60.0 & 31.4 to 88.6 \\
\hline $\operatorname{FVC}(n=5633)$ & 117.8 & 79.0 & 42.3 to 115.7 & 66.3 & 18.2 & -32.2 to 68.6 & 105.4 & 75.2 & 40.2 to 110.2 \\
\hline
\end{tabular}

SOB $=$ Shortness of breath.

"Unadjusted prevalence odds ratios (OR), presented for subjects in the 90th percentile versus those subjects in the 10th percentile of antioxidant intake- that is, for vitamin C intake $144.9 \mathrm{mg}$, for vitamin $\mathrm{E}$ intake $14.4 \mathrm{mg}$, and for $\beta$-carotene intake $2.50 \mathrm{mg}$.

tPrevalence odds ratios (with $95 \%$ confidence interval) adjusted for age, sex, energy intake, smoking status, pack years of smoking, presented for subjects in the 90th percentile versus those subjects in the 10th percentile of antioxidant intake.

${ }^{\ddagger}$ Difference in $\mathrm{FEV}_{1}$ and FVC (in $\mathrm{ml}$ for a standard height of $1.70 \mathrm{~m}$ ) between subjects in the 90th percentile and those in the 10th percentile of antioxidant intake adjusted for age, age squared, and sex.

${ }^{5}$ Difference in $\mathrm{FEV}_{1}$ and FVC (in ml for a standard height of $1.70 \mathrm{~m}$ ) with $95 \%$ confidence interval (95\% CI) between subjects in the 90 th percentile and those in the 10 th percentile of antioxidant intake adjusted for age, age squared, sex, energy intake, smoking status, pack years of smoking.

highest educational level. The dependent variables (respiratory symptoms, $\mathrm{FEV}_{1}$ and FVC) were also related to these factors. The prevalence of the respiratory symptoms was higher and the mean $\mathrm{FEV}_{1}$ and FVC was lower in current smokers than in never smokers. Lung function was also associated with educational level, with those in the high education category having better lung function. However, the prevalence of respiratory symptoms was not consistently different between educational levels.

The unadjusted prevalence of respiratory symptoms for each quintile of antioxidant intake and the unadjusted and adjusted mean of $\mathrm{FEV}_{1}$ and FVC for each quintile of antioxidant intake is presented in table 3 . There is no deviation from linearity. The results of logistic regression analysis with the intake of antioxidants as a continuous variable are presented in table 4 . The unadjusted and adjusted ORs for respiratory symptoms and the difference for $\mathrm{FEV}_{1}$ and FVC represent the comparison of subjects in the 90th percentile with those in the 10 th percentile of antioxidant intake. After adjustment for the considered confounding factors, the ORs of vitamin C intake with most of the symptoms were around 1 . The OR of vitamin $\mathrm{C}$ with cough was significantly below 1 ( $\mathrm{OR}=0.66 ; 95 \% \mathrm{CI} 0.50$ to 0.87$). \mathrm{FEV}_{1}$ was $53 \mathrm{ml}$ (95\% CI 23 to 82) higher in subjects with a high intake of vitamin $\mathrm{C}$ than in those with a low intake; for FVC the difference was $79 \mathrm{ml}$ (95\% CI 42 to 116). After adjustment the ORs of vitamin $\mathrm{E}$ intake with symptoms were around 1 with a significantly increased OR for productive cough $(\mathrm{OR}=1.26 ; 95 \% \mathrm{CI}$ 1.02 to 1.56$)$. Vitamin $\mathrm{E}$ intake was not associated with $\mathrm{FEV}_{1}$ and FVC. The adjusted ORs of the intake of $\beta$-carotene with symptoms were mostly around 1 with the exception of a significantly increased OR for wheeze $(\mathrm{OR}=1.27$; $95 \%$ CI 1.04 to 1.55$)$. However, $\mathrm{FEV}_{1}$ was 60 $\mathrm{ml}(95 \%$ CI 31 to 89$)$ higher in subjects with a high intake of $\beta$-carotene than in subjects with a low intake; for FVC the difference was $75 \mathrm{ml}$ (95\% CI 40 to 110 ).

The associations between the intake of vitamin $C$ or $\beta$-carotene and lung function did not change after adjustment for the intake of vitamin $\mathrm{E}$. 


\section{Discussion}

In the present study we observed that a high intake of vitamin $C$ and $\beta$-carotene, but not vitamin $\mathrm{E}$, was associated with a higher $\mathrm{FEV}_{1}$ and FVC than a low intake of these antioxidants. No consistent associations were observed with respiratory symptoms. This suggests that dietary vitamin $C$ and $\beta$-carotene have a protective effect on lung function but not on respiratory symptoms.

Lung function can be considered as a more objective measurement than respiratory symptoms. The lack of protective effect of vitamin C and $\beta$-carotene on respiratory symptoms might be due to reporting bias or due to an altered diet in those with respiratory symptoms. Another reason for the lack of agreement between the results on lung function and respiratory symptoms could be that the relevant lag time for a possible protective effect of antioxidants on lung function differs from that for respiratory symptoms.

Educational level was associated with the intake of antioxidants and with lung function but not with respiratory symptoms. This was not observed in other studies. ${ }^{79} 102223$ However, the present study showed that, after adjustment for educational level, the estimated effect between antioxidants and lung function decreased which suggests that educational level is a confounding factor. Since subjects in the high educational level are more likely to have a healthy life style which correlates also with a higher intake of antioxidants, we considered that educational level would be a healthy life style indicator which would lead to overadjustment of the relationship between antioxidants and lung function. Other more specific healthy life style factors such as physical activity, alcohol consumption, and body mass index did not materially affect the relationship between antioxidants and lung function.

The associations between antioxidant intake and respiratory symptoms or lung function may have been biased towards the null due to misclassification of exposure. As with most dietary assessment methods, semi-quantitative food frequency questionnaires have a tendency to random misclassification. In the present study we used a semi-quantitative food frequency questionnaire with correlations similar to those of other validated food frequency questionnaires. ${ }^{1823-26}$ However, the reproducibility and relative validity are often low leading to attenuation of the observed associations.

Subjects who did not meet ERS criteria for technically acceptable and reproducible lung function manoeuvres were excluded from the analyses of dietary antioxidants and lung function. This raises the question of selection bias. The relationship between antioxidants and respiratory symptoms was, however, not materially different between the total group and in the total group excluding subjects who did not meet ERS criteria. Although selection bias can not be totally excluded in the relationship between antioxidants and lung function, it does not seem very likely in this study.
The results of the present study with respect to the intake of antioxidants and respiratory symptoms can only be crudely compared with other studies because respiratory symptoms or disease as outcome were not completely comparable.

We did not find an association between most symptoms and the intake of vitamin C; only cough was significantly negatively associated with vitamin C. In the Nurses Health Study ${ }^{11}$ dietary vitamin $\mathrm{C}$ was not associated with the incidence of asthma. NHANES $\mathrm{II}^{10}$ did not show an association between dietary vitamin $\mathrm{C}$ and wheeze, but the amount of vitamin $C$ in the diet was associated with the presence of current bronchitis. A protective effect of serum vitamin C levels was observed with wheeze and current bronchitis. $^{10}$

We found that a high intake of vitamin $C$ was associated with a $53 \mathrm{ml}$ higher $\mathrm{FEV}_{1}$ and $79 \mathrm{ml}$ higher FVC than a low intake. This was consistent with the results of other studies investigating the intake of vitamin $\mathrm{C}^{7822}$ or plasma levels of vitamin $\mathrm{C}^{9}$ with lung function. Schwartz and Weiss ${ }^{8}$ and Britton and co-workers ${ }^{7}$ showed that a higher intake of vitamin $\mathrm{C}$ was associated with a higher $\mathrm{FEV}_{1}$; the size of the effect was of the same order of magnitude as in the present study. ${ }^{8}$ The magnitude of the association between vitamin $\mathrm{C}$ and FVC in the study of Britton and co-workers ${ }^{7}$ was also comparable to that of the present study. Dow and co-workers ${ }^{22}$ investigated the association between the intake of vitamin $\mathrm{C}$ and $\mathrm{FEV}_{1}$ and FVC. After additional adjustment for vitamin $\mathrm{E}$ the associations were of the same order of magnitude as in the present study and in those of Britton et $a l^{7}$ and Schwartz and Weiss, ${ }^{8}$ but were not statistically significant possibly because of the small sample size $(n=178)$. In summary, these studies suggest a protective effect of vitamin $\mathrm{C}$ intake on lung function but not on symptoms or disease as outcome.

The intake of vitamin $\mathrm{E}$ was not associated with most of the symptoms or with lung function. This is consistent with the study of Britton and co-workers ${ }^{7}$ which showed that the intake of vitamin $\mathrm{E}$ was not associated with $\mathrm{FEV}_{1}$ or FVC independent of the intake of vitamin C. In contrast, Dow and co-workers ${ }^{22}$ showed that the intake of vitamin $\mathrm{E}$ was positively associated with lung function independent of the intake of vitamin C. Troisi and co-workers observed that a higher intake of vitamin $\mathrm{E}$ was significantly associated with a lower incidence of asthma. ${ }^{11}$ Thus, the results of these few studies are not consistent.

The intake of $\beta$-carotene was not associated with the prevalence of symptoms in the present study. This is consistent with the Nurses Health Study which showed no association between the intake of carotene and the incidence of asthma. ${ }^{11}$ However, we observed that the intake of $\beta$-carotene was positively associated with $\mathrm{FEV}_{1}$ and FVC. To our knowledge no results on dietary $\beta$-carotene in relation to lung function have been published. The intake of total carotene was not associated with $\mathrm{FEV}_{1}, \mathrm{FVC}$, or the ratio of $\mathrm{FEV}_{1} / \mathrm{FVC}$ 
among 10416 subjects in a cross sectional study by Shahar and co-workers. ${ }^{27}$ They pointed out, however, that the different carotenoids may have different effects on lung physiology. Blood levels of $\beta$-carotene were related to lung function in two studies. A high level of $\beta$-carotene was not associated with airway obstruction $(\mathrm{n}=83) .{ }^{28}$ However, the pilot phase of the CARET study among 816 men exposed to asbestos showed that serum levels of $\beta$-carotene were positively associated with $\mathrm{FEV}_{1}$ and $\mathrm{FVC}^{21}$

In summary, the present study has shown that the intake of vitamin $C$ and $\beta$-carotene has a protective effect on lung function but not on respiratory symptoms. The findings on the intake of vitamin C are consistent with those of other studies. The intake of vitamin $\mathrm{E}$ had no effect on respiratory symptoms or lung function which was not completely consistent with the findings of other studies.

This study was financially supported by the Ministry of Public Health, Welfare and Sports of the Netherlands and the National Health, Welfare and Sports of the Netherlands and the National
Institute of Public Health and the Environment. The developInstitute of Public Health and the Environment. The develop-
ment of the food frequency questionnaire was supported by the ment of the food frequency questionnaire was supported by the Europe Against Cancer Programme of the European Union.
The authors wish to thank the epidemiologists and field workers The authors wish to thank the epidemiologists and field workers
of the Municipal Health Services in Amsterdam, Doetinchem, and Maastricht for their important contribution to the data collection for this study.

1 Burney P. The origins of obstructive airways disease. A role for diet? Am ₹ Respir Crit Care Med 1995;151:1292-3.

2 Hatch GE. Asthma, inhaled oxidants, and dietary antioxidants. Am f Clin Nutr 1995;61:625-30S.

3 Sridhar MK. Nutrition and lung health. Should people at risk of chronic obstructive lung disease eat more fruit and vegetables? $B M F$ 1995;310:75-6.

4 Strachan DP, Cox BD, Erzinclioglu SW, et al. Ventilatory function and winter fresh fruit consumption in a random sample of British adults. Thorax 1991;46:624-9.

5 Cook DG, Carey IM, Whincup PH, et al. Effect of fresh fruit consumption on lung function and wheeze in children. Thorax 1997;52:628-33.

6 Miedema I, Feskens EJM, Heederik D, et al. Dietary determinants of long-term incidence of chronic non-specific minants of long-term incidence of chronic non-specific
lung disease. The Zutphen study. Am $\mathcal{F}$ Epidemiol 1993; 138:37-45.

7 Britton JR, Pavord ID, Richards KA, et al. Dietary antioxidant vitamin intake and lung function in the general population. Am f Respir Crit Care Med 1995;151:1383-7.

8 Schwartz J, Weiss ST. Relationship between dietary vitamin $\mathrm{C}$ intake and pulmonary function in the first national health and nutrition examination survey (NHANES I). Am $\mathcal{F}$ Clin Nutr 1994;59:110-4.
9 Ness AR, Khaw KT, Bingham S, et al. Vitamin C status and respiratory function. Eur f Clin Nutr 1996;50:573-9.

10 Schwartz J, Weiss ST. Dietary factors and their relation to respiratory symptoms. Am f Epidemiol 1990;132:67-76.

11 Troisi RJ, Willett WC, Weiss ST, et al. A prospective study of diet and adult-onset asthma. Am $\mathcal{F}$ Respir Crit Care Med 1995;151:1401-8.

12 Burney PGJ, Luczynska C, Chinn S, et al. The European Community respiratory health survey. Eur Respir $\mathcal{F} 1994 ; 7$ 954-60.

13 Kerkhof M, de Graaf A, Droste JHJ, et al. The prevalence of asthma-like symptoms in three areas of the Netherlands (in Dutch). Tijdschrift Sociale Gezondheidszorg 1994;72:181-5.

14 Quanjer PhH, Tammeling GJ, Cotes JE, et al. Lung volumes and forced ventilatory flows: Report working party standardization of lung function tests European Community for Steel and Coal; official statement of the European Respiratory Society. Eur Respir f 1993;6:S5-40.

15 Berry MJ, McMurray RG, Katz VL. Pulmonary and ventilatory responses to pregnancy, immersion, and exercise. $\mathcal{F}$ Appl Physiol 1989;66:857-62.

16 Riboli E. Nutrition and cancer: background and rationale of the European Prospective Investigation into Cancer and Nutrition (EPIC). Ann Oncol 1992;3:783-91.

17 Ocké MC, Bueno de Mesquita HB, Goddijn HE, et al. The Dutch EPIC food frequency questionnaire I. Description of the questionnaire, and relative validity and reproducibility for food groups. Int $\mathcal{F}$ Epidemiol 1997;26: S37-48.

18 Ocké MC, Bueno de Mesquita HB, Pols MA, et al. The Dutch EPIC food frequency questionnaire II. Relative validity and reproducibility for nutrients. Int $\mathcal{F}$ Epidemiol 1997;26:S49-58.

19 Stichting NEVO. Nederlands voedingsstoffenbestand. 202nd edition. The Hague: Voorlichtingsbureau voor de voeding, 1993

20 SAS Institute Inc. SAS/STAT User's Guide. 4th edition. Cary: SAS Institute, 1996.

21 Chuwers P, Barnhart S, Blanc P, et al. The protective effect of $\beta$-carotene and retinol on ventilatory function in an asbestos-exposed cohort. Am F Respir Crit Care Med 1997; 155:1066-71

22 Dow L, Tracey M, Villar A, et al. Does dietary intake of vitamins $\mathrm{C}$ and $\mathrm{E}$ influence lung function in older people? $\mathrm{Am}$ J Respir Crit Care Med 1996;154:1401-4.

23 Bolton-Smith C, Casey CE, Gey KF, et al. Antioxidant vitamin intakes assessed using a food-frequency questionnaire: min intakes assessed using a food-frequency questionnaire: non-smokers. Br 7 Nutr 1991;65:337-46.

24 Coates RJ, Eley JW, Block G, et al. An evaluation of a food frequency questionnaire for assessing dietary intake of specific carotenoids and vitamin $\mathrm{E}$ among low-income black women. Am f Epidemiol 1991;134:658-71.

25 Jacques PF, Sulsky SI, Sadowski JA, et al. Comparison of micro-nutrient intake measured by a dietary questionnaire and biochemical indicators of micro-nutrient status. $A m \mathcal{F}$ Clin Nutr 1993;57:182-9.

26 Willett WC, Stampfer MJ, Underwood BA, et al. Validation of a dietary questionnaire with plasma carotenoid and of a dietary questionnaire with plasma carotenoid and

27 Shahar E, Folsom AR, Melnick SL, et al. Does dietary vitamin A protect against airway obstruction? Am $\mathcal{F}$ Respir Crit Care Med 1994;150:978-82.

28 Morabia A, Menkes MJS, Comstock GW, et al. Serum retinol and airway obstruction. Am $\mathcal{F}$ Epidemiol 1990;132:7782 